\title{
Analisis Sistem Distribusi Air Bersih di Perumahan Ciomas Permai Kabupaten Bogor Jawa Barat
}

\author{
(Analysis of Water Distribution System at Ciomas Permai Residence \\ Bogor Regency West Java)
}

\footnotetext{
Kiki Rizky Fauziah ${ }^{1}$, Nora Herdiana Pandjaitan ${ }^{*}$, dan Titiek Ujianti Karunia ${ }^{1}$

${ }^{1}$ Departemen Teknik Sipil dan Lingkungan, Fakultas Teknologi Pertanian, Institut Pertanian Bogor.

J1. Raya Dramaga, Kampus IPB Dramaga, PO BOX 220, Bogor, Jawa Barat, Indonesia

* Penulis korespondensi: norahp@apps.ipb.ac.id
}

\begin{abstract}
Water distribution systems are often problematic in terms of quantity, pressure, continuity and quality. The research aimed to analyze water distribution system of PDAM Tirta Kahuripan Kabupaten Bogor in Ciomas Permai Residence. The research was conducted by collecting primary and secondary data. Analysis of clean water distribution system was carried out using the EPANET 2.0. Ciomas Permai Residence was located in zone 6 of PDAM Tirta Kahuripan servive areas. The result showed that the quality of the distributed water was in accordance with the applicable standard and continuous for 24 hours even though there were significant discharge differences during peak hours. Based on the measurement on Sunday and Monday, the minimum discharge were $14.4 \mathrm{l} / \mathrm{sec}$ and $13.8 \mathrm{l} / \mathrm{sec}$ respectively, higher than customer requirements of $7.34 \mathrm{l} / \mathrm{sec}$, the water distribution pressure ranged from $0.7-1.35$ bar. The result of clean water distribution simulation using EPANET 2.0 showed that the velocity of water and headloss were not accordance with the applicable standards.
\end{abstract}

Keywords: Discharge, EPANET 2.0, Headloss, Pressure, Water Quality.

\section{PENDAHULUAN}

Seiring dengan pertambahan jumlah penduduk yang diikuti dengan pertambahan jumlah fasilitas sosial ekonomi maka kebutuhan air minum yang memenuhi standar kualitas dan kuantitas akan semakin meningkat. Menurut Peraturan Pemerintah Nomor 16 (PRI 2005), penyediaan air minum adalah kegiatan menyediakan air minum untuk memenuhi kebutuhan masyarakat agar mendapatkan kehidupan yang sehat, bersih dan produktif.

Untuk memenuhi kebutuhan air bersih maka sesuai Undang-Undang No.5 Tahun 1962 dibentuk Perusahaan Daerah Air Minum (PDAM). PDAM berfungsi sebagai perusahaan milik pemerintah daerah yang memberikan jasa pelayanan dalam bidang air minum. PDAM mendistribusikan air bersih dengan sistem perpipaan (Akhmad 2012). Kinerja pelayanan PDAM tidak lepas dari sistem distribusi yang merupakan suatu jaringan perpipaan yang tersusun atas sistem pipa, pompa, reservoir, dan perlengkapannya. Sistem distribusi air bersih sering bermasalah dalam hal kuantitas, tekanan, kontinyuitas dan kualitas air (Brebbia \& Ferrante 1983).

Perusahaan Daerah Air Minum (PDAM) Tirta Kahuripan terbagi dalam 12 cabang pelayanan. Adapun lokasi penelitian adalah wilayah Perumahan Ciomas Permai yang termasuk dalam daerah Pelayan PDAM Tirta Kahuripan Kab. Bogor cabang pelayanan VI Ciomas dengan pelanggan sebanyak 
12.859 sambungan aktif (Halief \& Putro 2017). Penelitian bertujuan untuk menganalisis sistem distribusi air bersih PDAM Tirta Kahuripan, Kabupaten Bogor di Perumahan Ciomas Permai dalam hal kualitas, kuantitas, kontinyuitas dan tekanan air. Ruang lingkup penelitian adalah kualitas, kuantitas, kontinyuitas dan tekanan air bersih yang menjadi tolak ukur dari kinerja sistem distribusi air bersih. $\begin{array}{lll}\text { Analisis dilakukan } & \text { dengan } \\ \text { menggunakan aplikasi EPANET } & 2.0 .\end{array}$

\section{METODOLOGI}

Penelitian ini dilaksanakan selama 5 bulan dari bulan Maret - Juli. Pengambilan data dilaksanakan mulai dari reservoir perumahan (inlet) sampai pipa pelayanan di rumah pelanggan. Perumahan Ciomas Permai memiliki luas kurang lebih 12.5 ha. Peta lokasi penelitian disajikan pada Gambar 1.

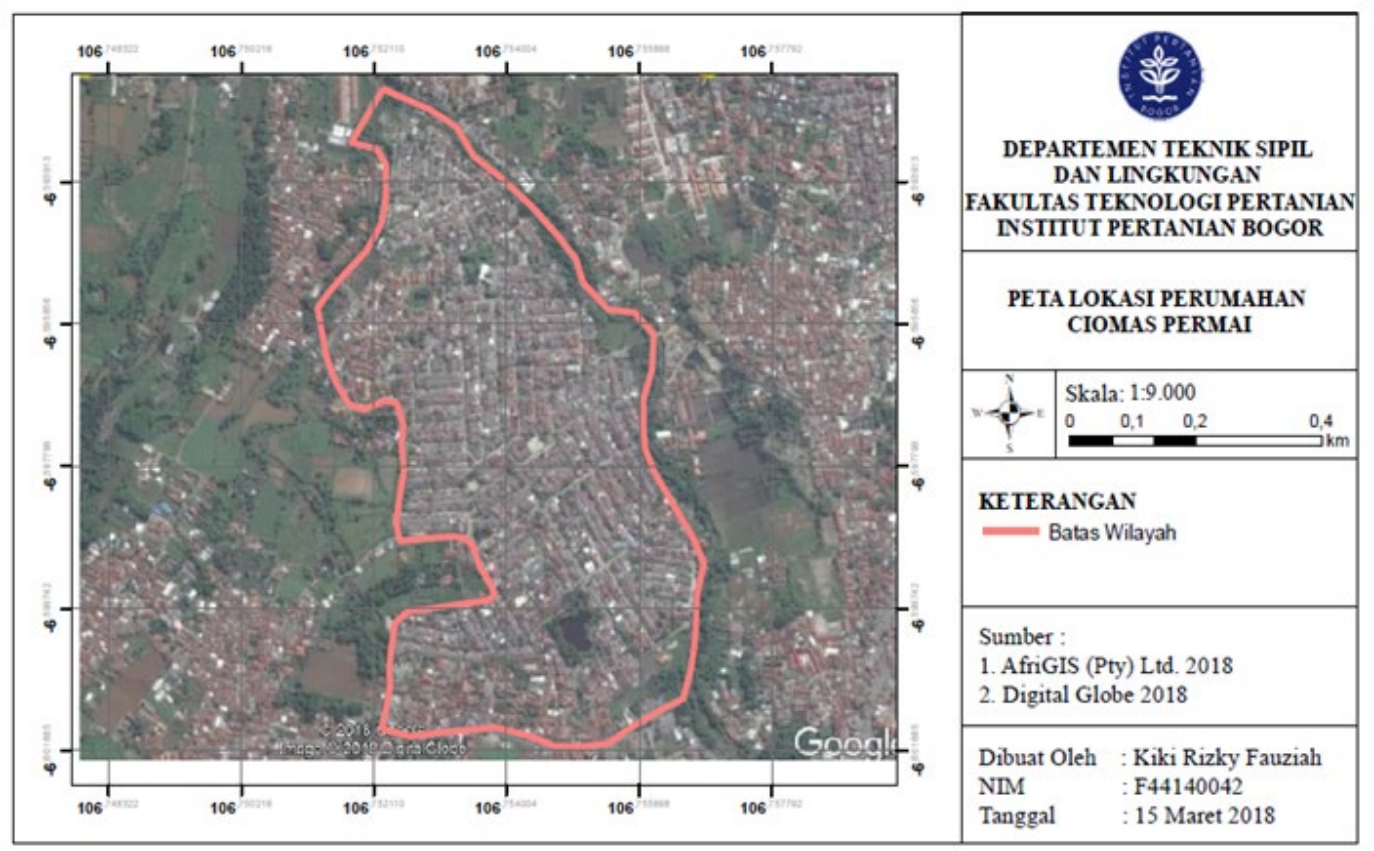

Gambar 1 Peta Lokasi Penelitian

Dalam penelitian ini alat yang digunakan adalah laptop yang dilengkapi dengan program Microsoft Excell, EPANET 2.0, alat tulis, kalkulator dan Global Positioning Sistem (GPS) tipe Garmin Oregon-550. Data yang dibutuhkan berupa data primer dan data sekunder. Data primer dikumpulkan melalui pengukuran, kuesioner dan pengamatan yang dilakukan pada wilayah penelitian. Data sekunder yang digunakan berupa peta wilayah pelayanan, peta jaringan pipa pelayanan air bersih, dan jumlah pelanggan serta data indikator kinerja PDAM Tirta Kahuripan. Pengumpulan data sekunder bertujuan untuk mendapatkan data-data yang membantu dalam menganalisis sistem distribusi PDAM Tirta Kahuripan. Metode ini digunakan untuk menentukan jumlah responden yang mewakili jumlah pelanggan yang ada di wilayah penelitian. Penentuan jumlah sampel dari total jumlah pelanggan menggunakan rumus Slovin seperti pada Persamaan (1). 
$n=\frac{N}{1+N e^{2}}$

Keterangan :

$\mathrm{n} \quad=$ jumlah sampel

$\mathrm{N}=$ ukuran populasi

e $\quad=$ batas ketelitian (1-10\%)

Pengolahan dan analisis data yang dilakukan mencakup identifikasi peta wilayah pelayanan dan peta jaringan pipa pelayanan air bersih. Setelah itu dilakukan analisis tentang kualitas, kuantitas, dan kontinyuitas air bersih, serta menghitung debit air dan tekanan pada wilayah pelayanan. Selain itu juga diidentifikasi kendala-kendala yang timbul pada sistem distribusi air bersih, dan dilanjutkan dengan membuat simulasi sistem distribusi air bersih dengan menggunakan aplikasi EPANET 2.0.

Studi pustaka dilakukan untuk mendapatkan pengetahuan dalam menganalisis permasalahan yang diteliti. Studi pustaka dilakukan dengan mempelajari publikasi ilmiah atau jurnal, dan laporan penelitian serta buku-buku yang terkait dengan topik penelitian.

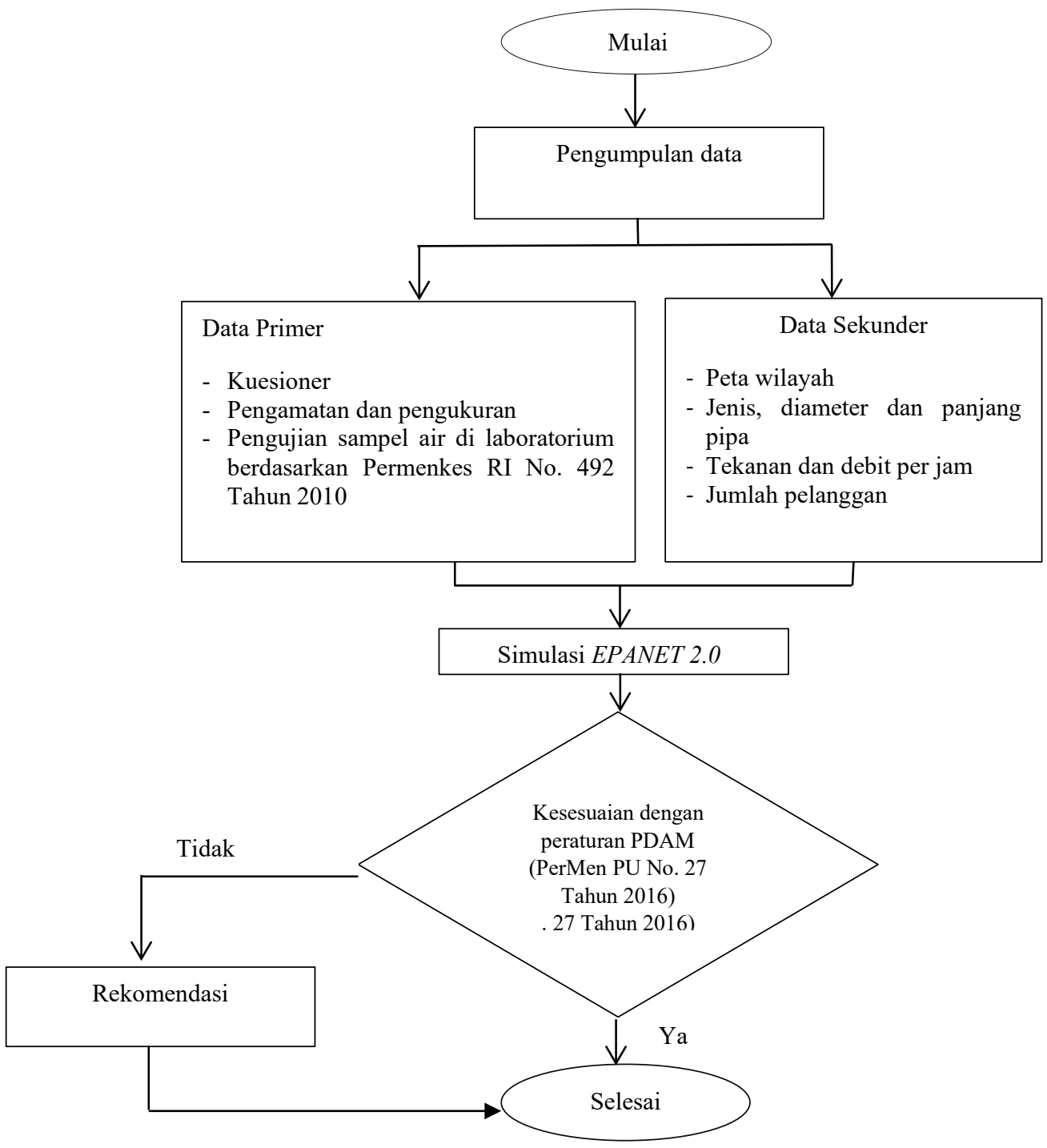

Gambar 2 Diagram Alir Penelitian 


\section{HASIL DAN PEMBAHASAN}

\section{Keadaan Umum Lokasi}

PDAM Tirta Kahuripan menyediakan air bersih pada cakupan Kabupaten Bogor, termasuk Perumahan Ciomas Permai yang terletak di Kecamatan Ciomas, Kabupaten Bogor. Perumahan Ciomas Permai termasuk ke dalam wilayah pelayanan zona 6 PDAM Tirta Kahuripan. Air yang didistribusikan ke Perumahan Ciomas Permai berasal dari reservoir Tirta Kahuripan Ciomas dengan kapasitas $4000 \mathrm{~m}^{3}$. Sumber air yang digunakan untuk suplai air di reservoir Tirta Kahuripan Ciomas berasal dari mata air Cikahuripan. Total pelanggan yang dilayani oleh reservoir Tirta Kahuripan Ciomas adalah 6002 rumah.

Jumlah air yang didistribusikan ke Perumahan Ciomas Permai setiap bulannya sebesar $23,000-25,000 \mathrm{~m}^{3}$. Air di reservoir diberikan desinfektan berupa $\mathrm{Ca}(\mathrm{ClO})_{2}$ atau kaporit sebelum didistribusikan ke pelanggan. Air dari outlet reservoir Tirta Kahuripan dialirkan ke inlet Perumahan Ciomas Permai secara gravitasi. Reservoir Tirta Kahuripan terletak pada elevasi 275 m dpl sementara Perumahan Ciomas Permai terletak pada elevasi $224 \mathrm{~m} \mathrm{dpl}$. Air yang didistribusikan dari reservoir memasuki Perumahan Ciomas Permai melalui 2 jalur inlet, yaitu yang berada di blok A dan blok C. Jaringan pipa di Perumahan Ciomas Permai menggunakan jenis pipa PVC.

\section{Keadaan Umum Responden}

Berdasarkan persamaan Slovin diperoleh jumlah responden sebanyak 95 orang untuk mewakili total pelanggan PDAM Tirta Kahuripan di lokasi penelitian yang berjumlah 1493 pelanggan. Hasil wawancara menunjukkan lebih dari $2 / 3$ total responden telah menjadi pelanggan PDAM Tirta Kahuripan selama lebih dari 10 tahun. Sebanyak 89 responden memanfaatkan air bersih untuk kegiatan rumah tangga (pribadi), sedangkan 6 responden menggunakan untuk keperluan usaha (niaga).

Kebocoran merupakan salah satu alasan pemberhentian air. Umumnya pemberhentian pasokan air akibat kebocoran air terbanyak terjadi selama 1 - 6 jam Sebanyak 35 responden pernah mengalami kebocoran pipa, sedangkan 60 responden lainnya tidak pernah mengalami kebocoran. Kebocoran air di Perumahan Ciomas Permai disebabkan oleh umur pipa (43\% responden) dan tekanan eksternal (43\% responden).

\section{Kinerja Sistem Distribusi}

Air bersih harus mempunyai kualitas tinggi secara fisik, kimiawi maupun biologi untuk mencegah timbulnya penyakit (Ikas 2013). Sebanyak 91\% responden menyatakan air yang didistribusikan bersih namun seringkali keruh saat terjadi hujan dan 94\% responden menyatakan air yang didistribusikan tidak berasa. Berdasarkan parameter fisik kebauan, sebanyak 94\% responden menyatakan bahwa air yang terdapat di Perumahan Ciomas Permai tidak berbau dan layak untuk digunakan. Air yang didistribusikan berbau bila ada sisa penambahan $\mathrm{Ca}(\mathrm{ClO})_{2}$ yang masih terbawa hingga ke pelanggan. Selain itu, bau juga dapat ditimbulkan oleh partikel tanah yang masih terbawa terutama saat musim hujan. 
Tabel 1 Data Hasil Pengujian Kualitas Air

\begin{tabular}{|c|c|c|c|c|c|c|}
\hline & \multirow{2}{*}{ Parameter } & \multirow{2}{*}{ Satuan } & \multirow{2}{*}{ Persyaratan } & \multicolumn{2}{|c|}{ Sampel } & \multirow{2}{*}{ Metode } \\
\hline & & & & $\mathrm{A}$ & B & \\
\hline \multicolumn{7}{|c|}{ Biologi } \\
\hline 1 & E.Coli & per $100 \mathrm{ml}$ & Maks 0 & 0 & 0 & $\begin{array}{l}\text { APHA ed. 22nd } \\
9222 \text { D.2012 }\end{array}$ \\
\hline \multicolumn{7}{|c|}{ Fisika } \\
\hline 2 & TDS & $m g / L$ & 500 & 58.9 & 57.9 & $\begin{array}{l}\text { Electrical } \\
\text { conductivity }\end{array}$ \\
\hline 3 & Suhu & ${ }^{\circ} \mathrm{C}$ & $\begin{array}{c} \pm 3^{\circ} \mathrm{C} \\
\text { dari } 23^{\circ} \mathrm{C}\end{array}$ & 23.1 & 23.9 & \\
\hline 4 & Kekeruhan & NTU & 5 & 0.5 & 0.2 & Nephelometer \\
\hline 5 & Sisa klor & $m g / L$ & Min 0.2 & 0.3 & 0.4 & \\
\hline \multicolumn{7}{|c|}{ Kimia } \\
\hline 6 & Besi $(\mathrm{Fe})$ & $m g / L$ & Maks 0.3 & 0.296 & 0.29 & $\begin{array}{l}\text { APHA ed. } 22 \text { nd } \\
3111 \text { B. } 2012\end{array}$ \\
\hline 7 & $\begin{array}{l}\text { Kesadahan } \\
\left(\mathrm{CaCO}_{3}\right)\end{array}$ & $m g / L$ & Maks 500 & 45.08 & 53.31 & $\begin{array}{l}\text { APHA ed. } 22 \text { nd } \\
3111 \text { B. } 2013\end{array}$ \\
\hline 8 & Nitrit $\left(\mathrm{NO}_{2} \mathrm{~N}\right)$ & $m g / L$ & Maks 3 & 0.005 & 0.006 & $\begin{array}{l}\text { APHA ed. } 22 \text { nd } \\
4500-N O 2 \text { B. } 2012\end{array}$ \\
\hline 9 & Nitrat $\left(\mathrm{NO}_{3} \mathrm{~N}\right)$ & $m g / L$ & Maks 50 & 1.86 & 1.34 & $\begin{array}{l}\text { APHA ed. 22nd } \\
4500-N O 3 \text { B. } 2013\end{array}$ \\
\hline 10 & Mangan (Mn) & $m g / L$ & Maks 0.4 & 0.062 & 0.077 & $\begin{array}{l}\text { APHA ed. } 22 \text { nd } \\
3111 \text { B. } 2013\end{array}$ \\
\hline 11 & $\mathrm{Ph}$ & & $6.5-8.5$ & 7.15 & 7.07 & $\begin{array}{l}\text { APHA ed. } 22 \text { nd } \\
4500-H \text { B. } 2013\end{array}$ \\
\hline 12 & Klorida & $m g / L$ & Maks 250 & 24 & 22 & $\begin{array}{l}\text { APHA ed. } 22 \text { nd } \\
3111 \text { B. } 2012\end{array}$ \\
\hline
\end{tabular}

Selain kualitas air secara fisik yang dianalisis, dilakukan pula penelitian kualitas air dengan pengujian secara langsung. Uji kualitas air meliputi parameter fisik, kimia dan mikrobiologis sesuai dengan standar yang berlaku (Gusril 2016). Sampel air diambil dari dua rumah konsumen di Perumahan Ciomas Permai pada bulan Mei dan Juli 2018. Hasil uji tersebut kemudian dibandingkan dengan standar kualitas air yang berlaku di Indonesia.

Sampel air bersih diperoleh pada rumah yang terletak di bagian tengah (kode sampel B) dan bagian belakang (kode sampel A) Perumahan Ciomas Permai. Berdasarkan hasil pengukuran pada Tabel 1, diperoleh hasil bahwa kualitas air di kedua rumah tersebut telah memenuhi baku mutu yang digunakan. Kuantitas air yang dialirkan di Perumahan Ciomas Permai dianalisis dengan kuesioner yang diberikan pada pelanggan serta pengukuran secara langsung. Berdasarkan kuesioner, sebanyak 55\% responden menyatakan bahwa debit air kecil pada saat jam puncak di pagi hari dan sore hari. Sebanyak 45\% responden di Ciomas Permai menyatakan tidak mengalami perbedaan debit air pada pagi dan sore hari.

Kebutuhan air bersih bervariasi tergantung kepada letak geografis, tingkat ekonomi, kebudayaan dan skala perkotaan. Perumahan Ciomas Permai memiliki total pelanggan sebanyak 1493 kepala keluarga. Apabila diasumsikan setiap keluarga memiliki 5 orang anggota keluarga, maka total jumlah pengguna air bersih di perumahan tersebut sebanyak 7.465 orang. Berdasarkan kategori kebutuhan air bersih yang berlaku, Perumahan Ciomas Permai dapat dikategorikan sebagai desa dengan asumsi jumlah konsumsi 
sebanyak 85 1t/org/hari. Jumlah konsumsi air dikalikan dengan total pengguna air bersih sehingga diperoleh kebutuhan air minimum di Perumahan Ciomas Permai sebesar 7.34 1/det.

Pengukuran debit dan tekanan air di Perumahan Ciomas Permai dilakukan pada hari Minggu dan Senin dengan masing - masing pengukuran dilakukan selama 24 jam. Berdasarkan data pengukuran tekanan dan debit selama 24 jam pada hari Minggu seperti yang disajikan pada Gambar 3, diperoleh debit minimum di inlet sebesar 14.4 1/det pada pukul 01.00 WIB, sedangkan debit puncak terjadi pada pukul 09.00 WIB yaitu sebesar 26.3 1/det. Nilai ini masih berada di atas nilai rata-rata kebutuhan air pelanggan sebesar 7.34 1/det sehingga dapat diketahui bahwa kebutuhan pelanggan di lokasi ini dapat dipenuhi. Grafik hubungan antara debit dan tekanan pada hari Senin selama 24 jam disajikan pada Gambar 4

Berdasarkan pengukuran debit dan tekanan yang dilakukan pada hari Senin, dapat diketahui bahwa jam puncak terjadi pada pukul 04.00 WIB yaitu dengan debit sebesar 31.0 1/det. Debit aliran minimum di inlet sebesar 13.8 1/det terjadi pada pukul 01.00 WIB. Debit air yang dialirkan di Perumahan Ciomas Permai berkaitan erat dengan aktivitas penggunaan air konsumen dan waktu penggunaan. Debit aliran air kembali naik pada pukul 16.00 WIB yaitu sebesar 29.4 1/det. Hal tersebut menunjukkan aktivitas penggunaan air yang kembali meningkat.

Debit aliran air umumnya tinggi pada saat penggunaan di pagi hari. Debit aliran air yang tinggi pada pagi hari berkaitan dengan penggunaan air oleh konsumen seperti mencuci serta mandi sebelum beraktivitas. Peraturan yang berlaku menetapkan bahwa kecepatan untuk air di dalam pipa PVC tidak lebih rendah dari $0.3 \mathrm{~m} /$ det untuk mencegah sedimentasi dan tidak lebih besar dari $4.5 \mathrm{~m} / \mathrm{det}$ untuk mencegah pengikisan dan headloss yang tinggi. Kecepatan aliran maksimum berdasarkan hasil pengukuran di lapangan untuk hari Minggu sebesar $3.24 \mathrm{~m} /$ det dan hari Senin sebesar 3.82 $\mathrm{m} /$ det.

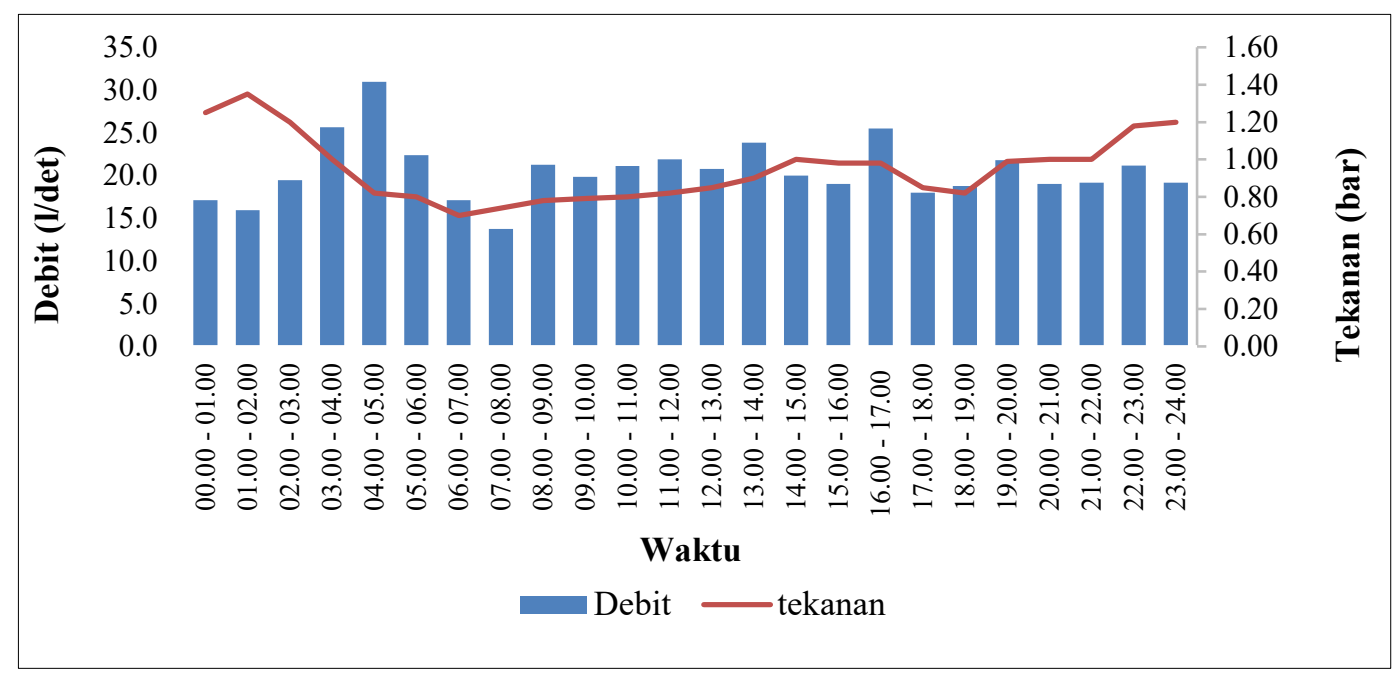

Gambar 3 Kurva Hubungan Debit dan Tekanan Selama 24 Jam pada Hari Minggu 


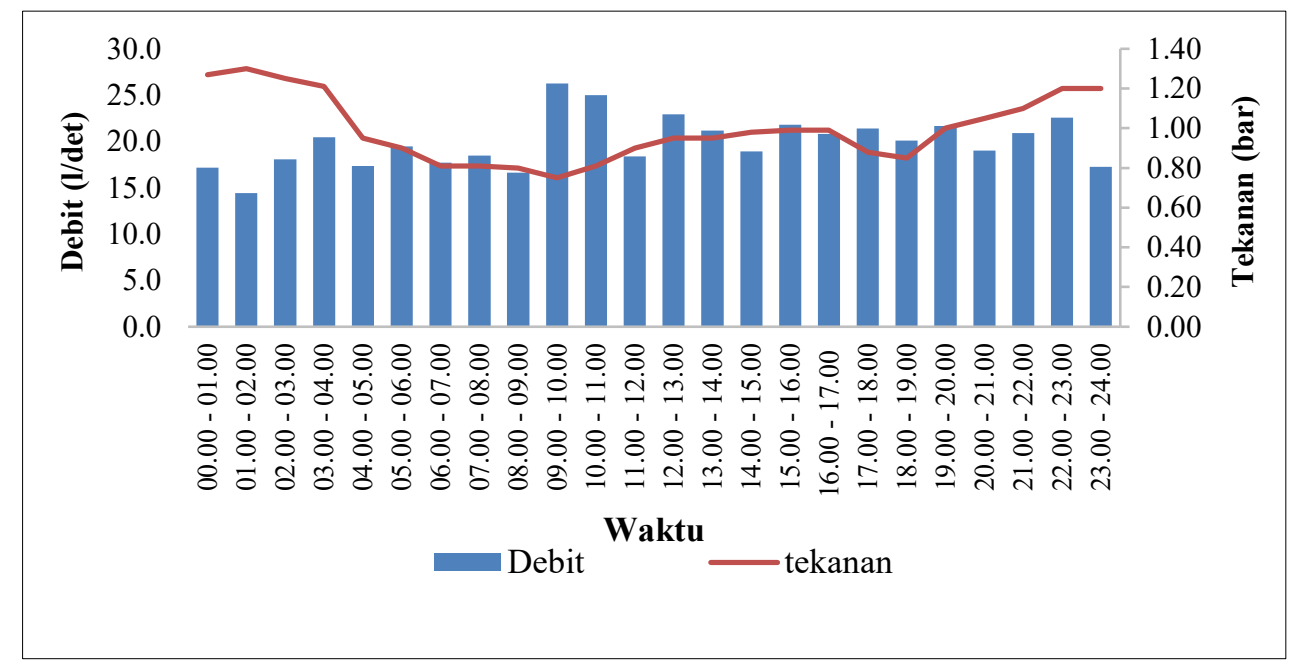

Gambar 4 Kurva Hubungan Debit dan Tekanan Selama 24 Jam pada Hari Senin

Hasil pengamatan di lokasi penelitian menunjukkan bahwa kontinyuitas air bersih baik karena tetap mengalir selama 24 jam walaupun ada perubahan debit air pada pagi dan sore hari. Hal tersebut dibuktikan dengan responden sebanyak $93 \%$ yang menyatakan bahwa air yang didistribusikan di Perumahan Ciomas Permai terus mengalir. Sebanyak 7\% responden tidak mendapatkan air secara penuh selama 24 jam, terutama pada pagi hari. Selain penggunaan air yang dilakukan secara bersamaan, perbedaan debit air juga disebabkan oleh faktor geografi.

\section{Tekanan}

Tekanan minimum yang diperlukan untuk mengalirkan air di dalam pipa PVC berdasarkan PerMenPU No. 27 Tahun 2016 adalah 0.5 bar - 1 bar dengan nilai maksimum sebesar 8 bar. Tekanan memiliki kaitan yang erat dengan debit aliran. Kurva hubungan antara tekanan dan debit aliran di inlet disajikan pada Gambar 3 dan Gambar 4. Berdasarkan data pengukuran tekanan yang telah dilakukan selama 24 jam, diperoleh tekanan tertinggi terjadi pada pukul 01.00 WIB yaitu sebesar 1.30 bar. Penggunaan debit pemakaian yang tinggi pada outlet pipa menyebabkan tekanan dalam pipa di suatu titik tertentu mengalami penurunan dan tekanan mengalami kenaikan pada saat debit pemakaian menurun (Murdi 2017).

Tekanan air terendah pada pengukuran di hari Senin terjadi pada pukul 06.00 WIB yaitu sebesar 0.7 bar. Pada jam pemakaian minimum yaitu pada pukul $12.00 \mathrm{WIB}$, tekanan air yang terjadi sebesar 0.85 bar. Pengukuran di hari Senin yang termasuk ke dalam weekdays menunjukkan debit dan tekanan memiliki hubungan yang berbanding lurus dan tidak sesuai dengan literatur yang ada. Data pengukuran yang diperoleh pada hari Minggu dan Senin memenuhi persyaratan yaitu berada di atas 0.5 bar dan di bawah 8 bar.

\section{Simulasi EPANET 2.0}

Aplikasi EPANET 2.0 digunakan untuk menganalisa aliran air di dalam pipa. Parameter yang dapat dianalisa berupa tekanan, head, debit dan kualitas air. Jaringan perpipaan yang digunakan pada aplikasi EPANET 2.0, dibuat dengan mengikuti peta jaringan perpipaan seperti yang terdapat pada Gambar 5. Dalam simulasi digunakan 1 reservoir dengan dua buah jalur utama 
pendistribusian air di Perumahan Ciomas Permai. Selain itu, dibuat 167 node dan 166 pipa yang mencakup seluruh pelanggan yang ada di Perumahan Ciomas Permai.

Simulasi EPANET 2.0 membutuhkan data - data spesifik berupa total head pada reservoir, base demand pada setiap node, panjang pipa, diameter pipa dan kekasaran pipa. Multipliers atau faktor pengali merupakan faktor untuk tiap periode dari pattern. Rata - rata multipliers yang di input pada demand pattern EPANET 2.0 untuk hari Minggu dan Senin sebesar 1. Nilai kebutuhan air yang berada di atas nilai 1.0 untuk hari Minggu dan Senin menunjukkan permintaan air yang tinggi, sedangkan nilai yang berada di bawah nilai tersebut menunjukkan permintaan air yang rendah berdasarkan waktu penggunaan tiap jam selama 24 jam di Perumahan Ciomas Permai.

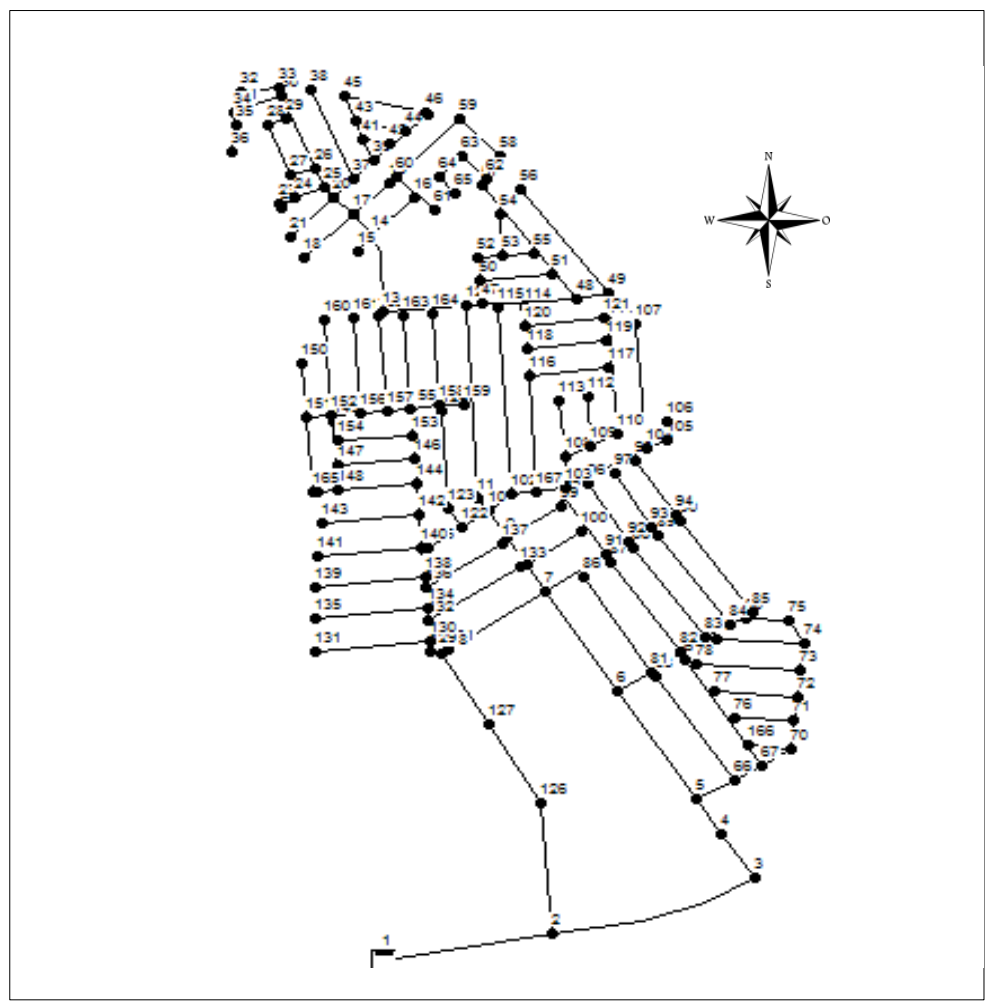

Gambar 5 Jaringan Perpipaan pada EPANET 2.0

Simulasi EPANET 2.0 dapat dilaksanakan setelah melakukan input data. Berdasarkan hasil simulasi, diperoleh nilai tekanan, headloss, debit dan kecepatan air. Simulasi tekanan dan debit untuk hari Minggu disajikan pada Gambar 6 dan untuk hari Senin disajikan pada Gambar 7. Tekanan air yang diperoleh dari hasil simulasi EPANET 2.0 masih memiliki nilai minimum yang lebih kecil dari persyaratan pada PerMenPU No. 27 Tahun 2016 yaitu sebesar 0.6 bar. Data rata - rata hasil simulasi dari EPANET 2.0 pada bagian junction atau node disajikan pada Tabel 2. 
Tabel 2 Data Rata - rata Hasil Simulasi dari EPANET 2.0 pada Junction

\begin{tabular}{|c|c|c|c|c|c|}
\hline \multirow[b]{2}{*}{ Hari } & \multirow[b]{2}{*}{ Waktu (WIB) } & \multicolumn{4}{|c|}{ Node } \\
\hline & & $\begin{array}{c}\text { Permintaan } \\
1 / \mathrm{dt}\end{array}$ & $\begin{array}{l}\text { Head } \\
(\mathrm{m})\end{array}$ & $\begin{array}{l}\text { Tekanan } \\
\text { (bar) }\end{array}$ & $\begin{array}{c}\text { Sisa klor } \\
\mathrm{mg} / \mathrm{L}\end{array}$ \\
\hline \multirow{3}{*}{ Minggu } & $01.00-02.00$ (minimum) & 0.06 & 31.28 & 31.11 & 0.01 \\
\hline & $09.00-10.00$ (puncak) & 0.10 & 50.36 & 50.19 & 0.26 \\
\hline & $18.00-19.00$ (normal) & 0.07 & 40.97 & 40.81 & 0.27 \\
\hline \multirow{3}{*}{ Senin } & $04.00-05.00$ (puncak) & 0.12 & 56.21 & 56.04 & 0.26 \\
\hline & $07.00-08.00$ (minimum) & 0.05 & 29.02 & 28.85 & 0.24 \\
\hline & $12.00-13.00$ (normal) & 0.07 & 40.97 & 40.81 & 0.27 \\
\hline
\end{tabular}

Berdasarkan data simulasi EPANET 2.0 pada Tabel 2 untuk waktu penggunaan air pada hari Minggu yaitu pukul 01.00 WIB, tekanan rata - rata pada pipa sebesar 3.11 bar. Debit aliran air yang dialirkan untuk dikonsumsi pelanggan pada jam puncak berdasarkan simulasi di EPANET 2.0 sebesar 16.2 $1 /$ det. Debit dan tekanan hasil simulasi memiliki nilai berbanding lurus yang dapat disebabkan oleh perlakuan pada program EPANET $2.0 \quad$ yang mengasumsikan bahwa seluruh jaringan perpipaan terbuka. Jam puncak untuk hari Senin terjadi pada pukul 04.00 WIB. Berdasarkan data simulasi EPANET 2.0 pada Tabel 2, tekanan rata - rata pada hari Senin sebesar 5.6 bar. Tekanan yang diperoleh untuk simulasi EPANET 2.0 tidak memenuhi baku mutu yang terdapat dalam literatur.

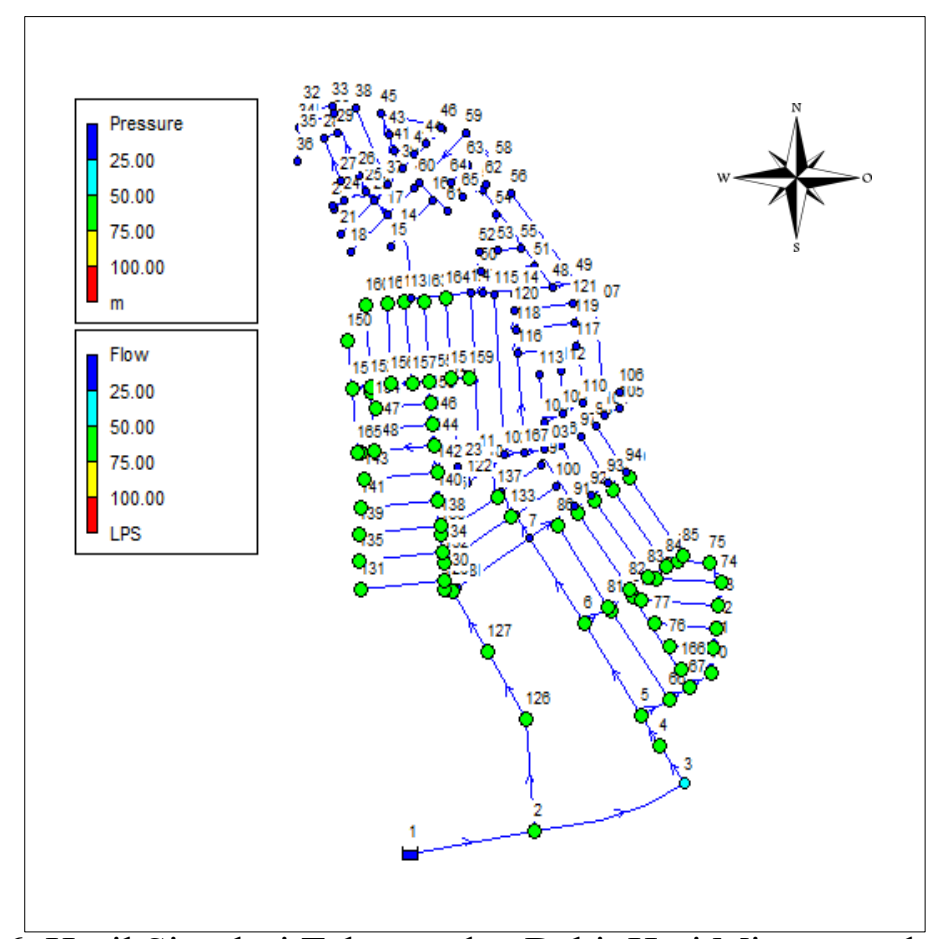

Gambar 6 Hasil Simulasi Tekanan dan Debit Hari Minggu pada EPANET 2.0 


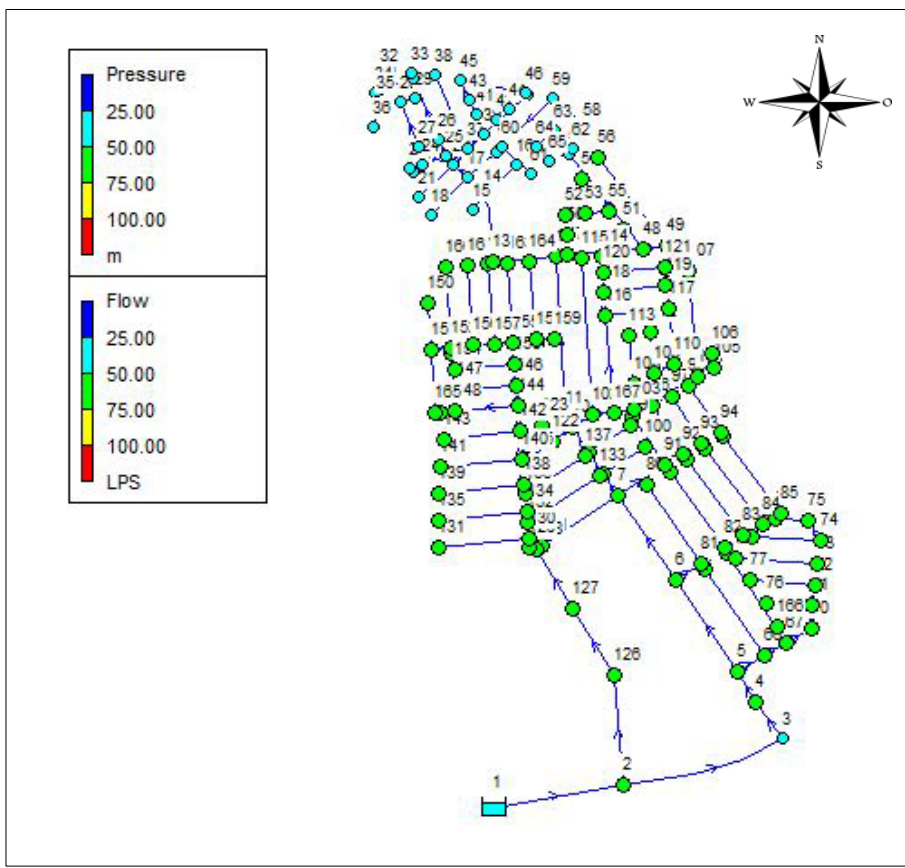

Gambar 7 Hasil Simulasi Tekanan dan Debit Hari Senin pada EPANET 2.0

Tabel 3 Rata - rata Hasil Simulasi dari EPANET 2.0 pada Pipa

\begin{tabular}{cccccc}
\hline Hari & Waktu (WIB) & Kekasaran $(\mathrm{C})$ & $\begin{array}{c}\text { Debit } \\
(\mathrm{l} / \mathrm{dt})\end{array}$ & $\begin{array}{c}\text { Kecepatan } \\
(\mathrm{m} / \mathrm{s})\end{array}$ & $\begin{array}{c}\text { Headloss } \\
(\mathrm{m} / \mathrm{km})\end{array}$ \\
\hline \multirow{3}{*}{ Minggu } & $01.00-02.00$ & 125.00 & 0.65 & 0.17 & 2.40 \\
& $09.00-10.00$ & 125.00 & 1.17 & 0.30 & 7.20 \\
& $18.00-19.00$ & 125.00 & 0.90 & 0.23 & 4.39 \\
\hline \multirow{3}{*}{ Senin } & $04.00-05.00$ & 125.00 & 1.34 & 0.34 & 9.24 \\
& $07.00-08.00$ & 125.00 & 0.60 & 0.15 & 2.05 \\
& $12.00-13.00$ & 125.00 & 0.90 & 0.23 & 4.39 \\
\hline
\end{tabular}

Headloss tertinggi pada jam puncak di hari Minggu terdapat pada pipa 86 dengan kecepatan air sebesar $1.73 \mathrm{~m} /$ det. Headloss pada pipa akan meningkat seiring dengan meningkatnya kebutuhan air. Kebutuhan yang tinggi pada jam puncak menyebabkan headloss akan bernilai tinggi. Hasil simulasi EPANET 2.0 untuk nilai headloss hari Minggu disajikan pada Gambar 8 dan untuk hari Senin pada jam puncak yaitu pukul 04.00 WIB disajikan pada Gambar 9. Berdasarkan data pada Tabel 3, dapat diketahui bahwa nilai headloss yang terjadi pada jam puncak memiliki nilai rata - rata sebesar $9.24 \mathrm{~m}$ per $\mathrm{km}$ sedangkan pada pemakaian minimum sebesar $2.05 \mathrm{~m}$ per $\mathrm{km}$. Headloss berbanding terbalik dengan diameter pipa, karena semakin kecil diameter pipa maka headloss yang dihasilkan akan semakin besar (Karunia 2013). Faktor friksi atau koefisien gesekan yang terjadi memiliki perbandingan lurus dengan headloss yang terjadi di sepanjang pipa. 


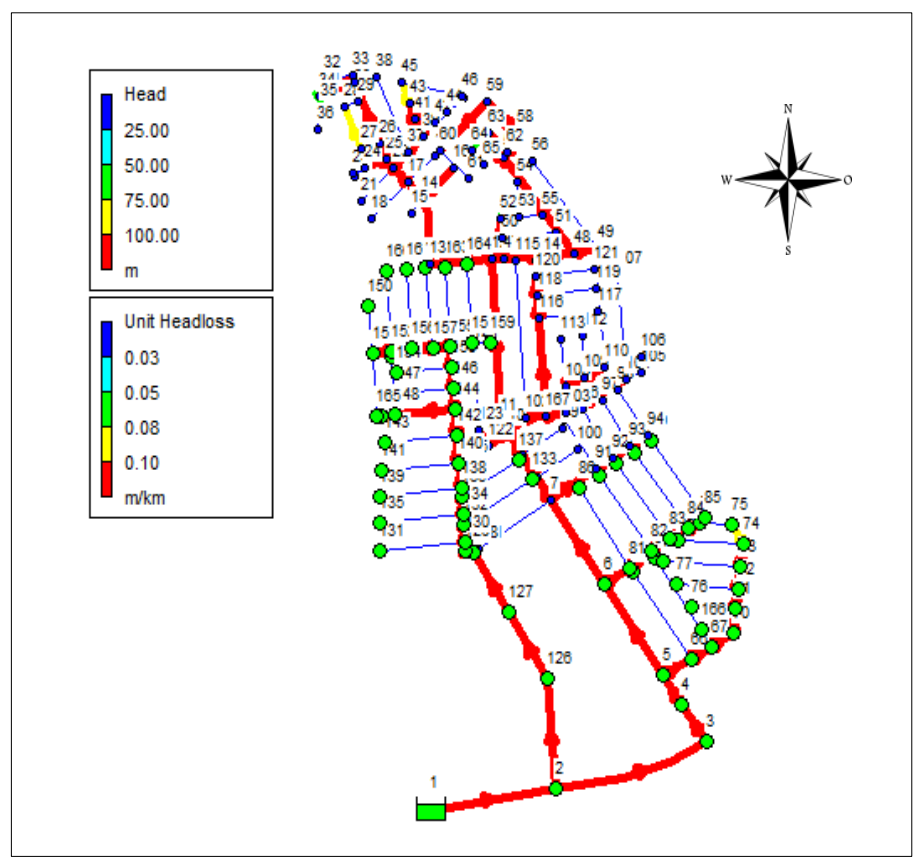

Gambar 8 Hasil Simulasi Head dan Headloss Hari Minggu pada EPANET 2.0

Berdasarkan peraturan yang berlaku headloss maksimum tidak boleh melebihi $15 \mathrm{~m}$ per $\mathrm{km}$. Nilai headloss yang terjadi pada node masih ada yang nilainya melebihi $15 \mathrm{~m}$ per $\mathrm{km}$. Kecepatan aliran minimum pada simulasi EPANET 2.0 sebesar $0.1 \mathrm{~m} / \mathrm{det}$ dan tidak memenuhi persyaratan karena lebih rendah dari standar kecepatan yang ditentukan yaitu $0.3 \mathrm{~m} /$ det. Kecepatan air yang kecil menunjukkan bahwa kuantitas air yang didistribusikan tidak seimbang dengan permintaan air di Perumahan Ciomas Permai.

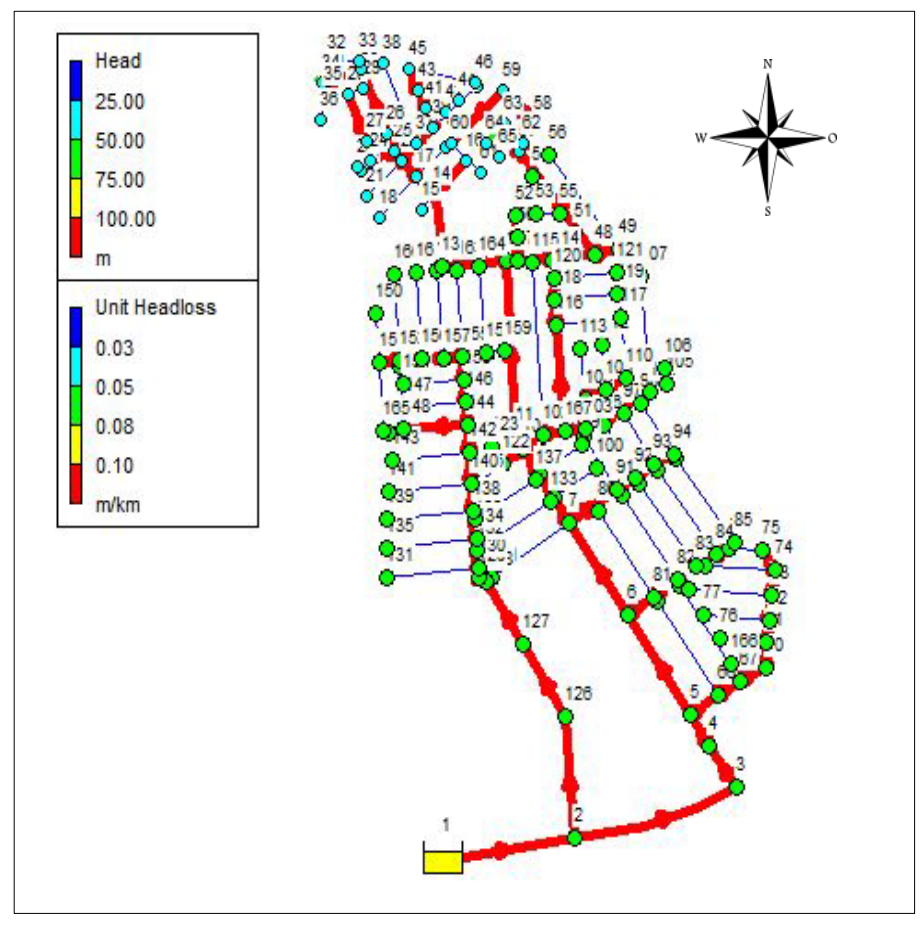

Gambar 9 Hasil Simulasi Head dan Headloss Hari Senin pada EPANET 2.0 


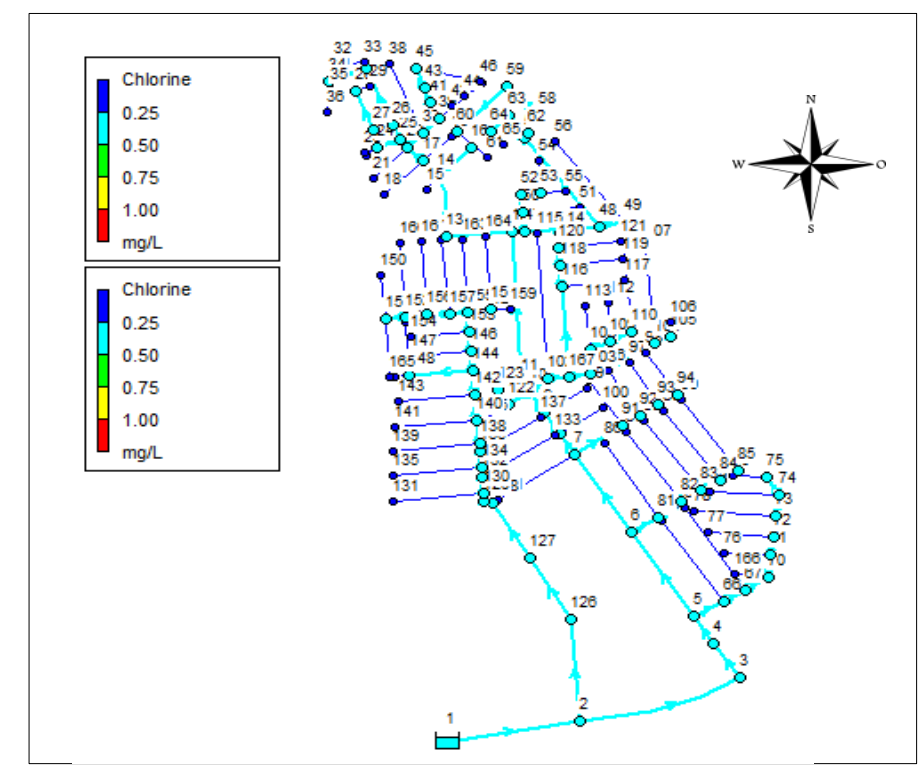

Gambar 10 Hasil Simulasi Sisa Klor Hari Minggu pada EPANET 2.0

Kualitas air bersih yang disimulasi di dalam EPANET 2.0 adalah sisa klor. Pengukuran sisa klor pada hari Minggu disajikan pada Gambar 10. Pada waktu penggunaan air minimum di hari Minggu nilai rata rata sisa klor sebesar $0.01 \mathrm{mg} / \mathrm{L}$. Simulasi sisa klor pada hari Senin disajikan pada Gambar 11. Berdasarkan hasil simulasi, nilai sisa klor rata - rata untuk jam puncak di hari Senin sebesar
$0.26 \mathrm{mg} / \mathrm{L}$. Nilai rata - rata sisa klor pada pemakaian minimum di hari Minggu berada di bawah persyaratan PerMenKes RI No. 492 Tahun 2010 . Keberadaan sisa klor bebas di dalam jaringan distribusi apabila kurang dari $0.2 \mathrm{mg} / \mathrm{L}$ menyebabkan kemampuan desinfektan berkurang sehingga jumlah patogen pun meningkat (Sofia et al. 2015).

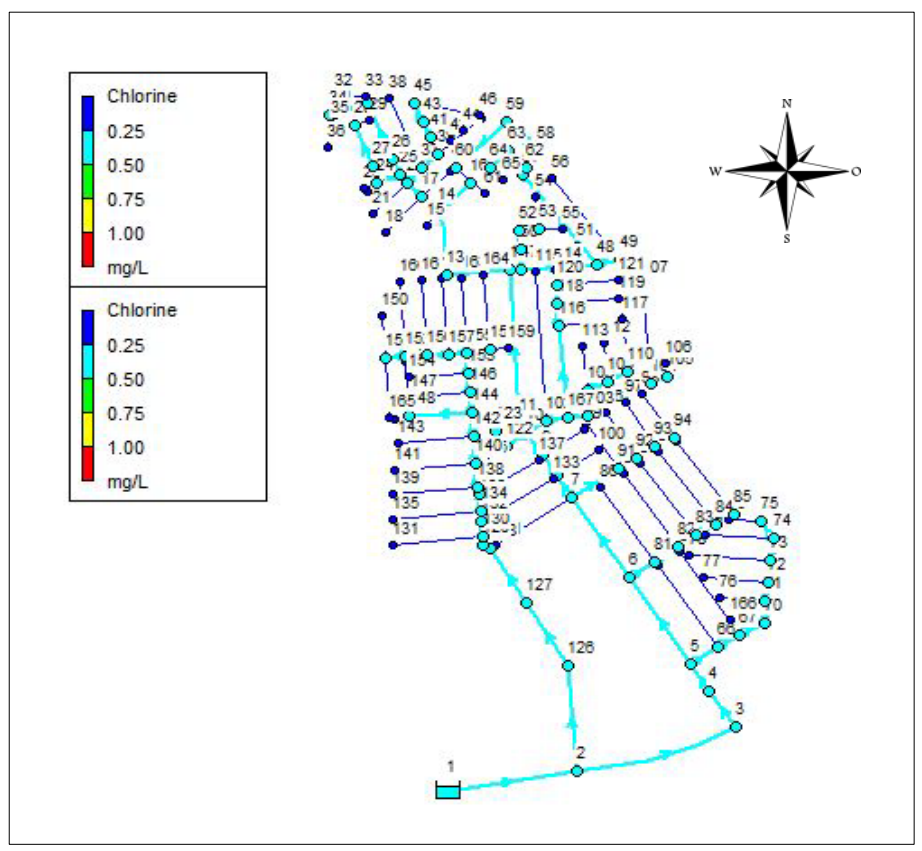

Gambar 11 Hasil Simulasi Sisa Klor Hari Senin pada EPANET 2.0 


\section{KESIMPULAN}

Perumahan Ciomas Permai termasuk ke dalam zona 6 pada PDAM Tirta Kahuripan. Berdasarkan penelitian yang telah dilakukan, diperoleh kualitas air di lapangan telah sesuai dengan Permenkes No. 492/Menkes/Per/IV/2010 dan kontinyu selama 24 jam walaupun terdapat perbedaan debit yang signifikan saat jam puncak. Berdasarkan pengukuran debit dan tekanan air di Perumahan Ciomas Permai yang dilakukan pada hari Minggu dan Senin diperoleh debit minimum sebesar 14.4 1/det dan 13.8 1/det dengan tekanan berkisar antara 0.7 - 1.35 bar. Nilai ini melebihi nilai ratarata kebutuhan air pelanggan berdasarkan perhitungan kebutuhan air di Perumahan Ciomas Permai yaitu sebesar 7.34 1/det. Pada simulasi distribusi air bersih menggunakan EPANET 2.0 didapatkan bahwa air yang didistribusikan kontinyu selama 24 jam walaupun kualitas air tidak memenuhi persyaratan kualitas air yang berlaku. Kecepatan air dan headloss berdasarkan simulasi tidak memenuhi Permen PU No. 27 Tahun 2016 karena kecapatan air kurang dari $0.3 \mathrm{~m} /$ det dan headloss melebihi $15 \mathrm{~m}$ per $\mathrm{km}$.

\section{DAFTAR PUSTAKA}

[PRI] Pemerintah Republik Indonesia. 2005. Pengembangan Sistem Penyediaan Air Minum. Peraturan Pemerintah Republik Indonesia Nomor 16 Tahun 2005. Jakarta (ID): Pemerintah Republik Indonesia.

Akhmad AF. 2012. Mempelajari kehilangan head pada pipa distribusi jaringan suplai air bersih PDAM Tirta Kahuripan. [skripsi]. Bogor: Institut Pertanian Bogor.
Brebbia C, Ferrante A. 1983. Numerical Methods in Fluid Dynamics. New York (NY): Pentech Press.

Halief K, Putro H. 2017. Analisis tingkat kepuasan pelanggan rumah tangga pada Perusahaan Daerah Air Minum (PDAM) Tirta Kahuripan cabang Pelayanan VI. Jurnal Desain Konstruksi. 16(1): 22-32.

Ikas. 2013. Studi jaringan air bersih PDAM di Kecamatan Pontianak Tenggara. Jurnal Teknik Sipil UNTAN. 13(2): 367-378.

Gusril H. 2016. Studi kualitas air minum PDAM di Kota Duri Riau. Jurnal Geografi. 8(2): 190-196.

Karunia TU. 2013. Analisis sistem disitribusi air bersih di Perumahan Taman Yasmin Sektor Enam Bogor, Jawa Barat. [skripsi]. Bogor : Institut Pertanian Bogor.

Murdi AS. 2017. Analisi tekanan debit pada pipa distribusi sistem air bersih PDAM Tirta Pakuan Bogor. [skripsi]. Bogor : Institut Pertanian Bogor.

Sofia E, Rony R, Chairul A. 2015. Evaluasi keberadaan sisa klor bebas di jaringan distribusi IPA Sungai Lulut PDAM Bandarmasih. Jukung Jurnal Teknik Lingkungan. 1(1): 33-52. 
